\title{
A Model Based on Linguistic of Transferring Qualified Personnel Resource to Qualified Personnel Capital
}

\author{
Weiya Miao' ${ }^{1}$ Linxiang Zhang ${ }^{2}$ \\ 1.School of Management, Electronic University of Science and Technology of China, Chengdu 610054, China \\ 2. Luzhou committee organizing department of CCP, Luzhou 64600, China
}

\begin{abstract}
This paper presents a model based on linguistic value for the transform from qualified personnel resource to qualified personnel capital. It is important to transform from qualified personnel resource to qualified personnel capital for transferring the mode of economic increase in many countries. The model of fuzzy comprehensive evaluation is established to explain the method of comprehensive benefitevaluation for the transform from qualified personnel resource to qualified personnel capital. However, the model based on linguistic value is better than the fuzzy comprehensive evaluation to explain people's habit of thought.
\end{abstract}

Keywords: Qualified personnel resource, Qualified personnel capital, Benefit-evaluation, Linguistic evaluation

\section{Introduction}

Transferring qualified personnel resource to qualified personnel capital is one of the key contents of knowledge economy, and realizing the transformation is also one of the major contents of research on qualified personnel resource management. As is well known, the qualified personnel resource has become the most important resource that can develop continuously at present, and the qualified personnel capital has been becoming one of the crucial factors of the enterprise, regional economy and even the national comprehensive competition. Transferring qualified personnel resource to qualified personnel capital is an important measure to realize countries' socioeconomic sustainable development, so it has important theory with actual meanings of study on the evaluation of transferring qualified personnel resource to qualified personnel capital (Beker, 1962; Alexander, 1983; Amit \& Belcourt, 1999; Ban-dyopadhyay, 2003; Schultz, 2003). It's not only existing many factors with fuzzy information and stochastic information in the process of transferring the qualified personnel resource to qualified personnel capital, but also is facing with many difficulties in the process of analyzing the comprehensive benefit of the transformation. Therefore, it's necessary to establish the theory and methods that can handle the evaluation of transferring qualified personnel resource to qualified personnel capital, which is multifactor and of diversified benefit forms.

It is very important to explain the principle of the transferring qualified personnel resource to qualified personnel capital because there are many factors with qualitative information in the process of evaluation. In fact, people usually use the linguistic tool to process qualitative information (Herrera, 2000; Zadeh, 1996; Yang Xu, etc., 2003, 2004).

This paper aims at discussing an evaluation model based on linguistic variable. In this paper, we present a basic mathematics model of transferring qualified personnel resource to qualified personnel capital based on linguistic.

The organization of this paper is as follows. The basic model based on linguistic of transferring qualified personnel resource to qualified personnel capital is introduced in section 2, and this section includes six aspects of contents, such as the process and the model of transferring qualified personnel resource to qualified personnel capital; depiction of social benefit; depiction of economic benefit; depiction of quality; depiction of potentiality; and depiction of the construction of ability. Section 3 is conclusions that explain the advantage of the model based on linguistic and some suggestions of transferring qualified personnel resource to qualified personnel capital.

\section{The basic model based on linguistic}

What the transform from qualified personnel resource to qualified personnel capital is transferring the quality and ability of personnel resource to economic and 
social benefit of qualified personnel capital through a certain social condition, and this process is shown as Fig.1.

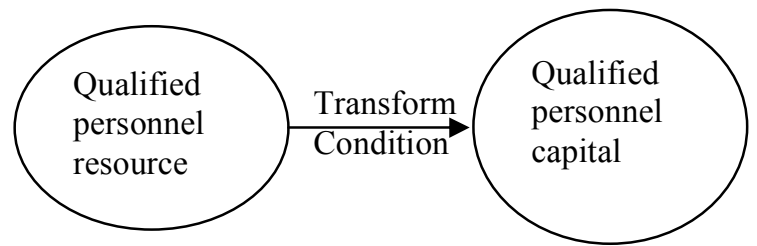

Fig.1: The process of the transferring qualified personnel resource to qualified personnel capital.

The model of transferring qualified personnel resource to qualified personnel capital is shown as Fig.2.

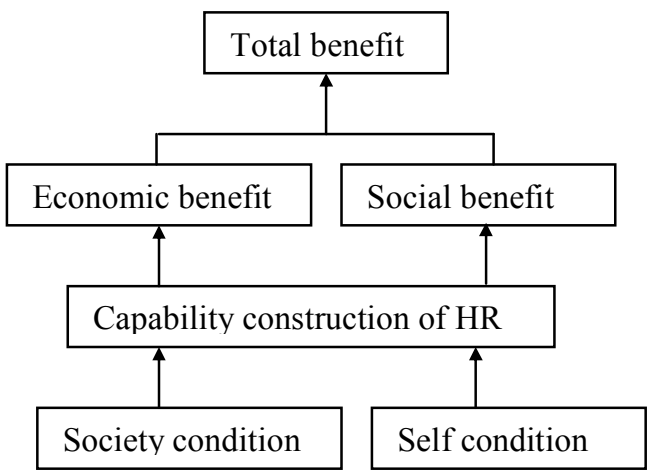

Fig.2: the model of transferring qualified personnel resource to qualified personnel capital.

Suppose (1) Total benefit = S (social benefit, economic benefit).

To study the principle of the transform from qualified personnel resource to qualified personnel capital, normally it can be depicted to solve the following optimization problem:

Goal: Max S (social benefit, economic benefit) condition: Subject to: Related to condition. Where, S is a binary monotone increasing (based on the common understanding order, in the same way hereinafter.) linguistic-valued mapping, which can be depicted as follows.

Suppose that (1) The linguistic value sets of evaluation for social benefit and economic benefit are both \{little, middling, big\}, S can be given by Table 1 .

\begin{tabular}{|c|l|l|l|}
\hline S & Little & Middling & Big \\
\hline Little & Little & Little & Middling \\
\hline Middling & Little & Middling & Big \\
\hline Big & Middling & Big & Big \\
\hline
\end{tabular}

Table 1: the result of $\mathrm{S}$.

\subsection{Depiction of social benefit}

Social benefit $=\mathrm{S} 1$ (the quantity of qualified personnel capital in social benefit, the quality of qualified personnel capital in social benefit),

where, $\mathrm{S}$ is a binary monotone increasing linguisticvalued mapping, which can be depicted as follows.

Suppose (1) The linguistic set of the quantity of qualified personnel capital in social benefit is \{little, middle, big . (2) The linguistic set of the quality of qualified personnel capital in social benefit is $\{\mathrm{bad}$, fair, good, excellent\}.

S1 can be given by Table 2 .

\begin{tabular}{|l|l|l|l|l|}
\hline \multicolumn{1}{|c|}{ S1 } & Bad & Fair & Good & Excellent \\
\hline Little & Little & Little & Middling & Middling \\
\hline Middling & Little & Middling & Middling & Big \\
\hline Big & Middling & Middling & Big & Big \\
\hline
\end{tabular}

Table 2: the result of $\mathrm{S} 1$

The quantity of qualified personnel capital in social benefit $=\mathrm{F} 1$ (quality, potentiality) where, F1 is a binary monotone increasing linguisticvalued mapping, which can be depicted as follows.

Suppose that

(1) The linguistic value set of evaluating quality is \{bad, fair, good, excellent $\}$.

(2)The linguistic value set of evaluating potentiality is \{little, middling, big\}.

F1 can be given by Table 3 .

\begin{tabular}{|l|l|l|l|}
\hline F1 & Little & Middling & Big \\
\hline Bad & Little & Little & Middling \\
\hline Fair & Little & Middling & Middling \\
\hline Good & Middling & Middling & Big \\
\hline Excellent & Middling & Big & Big \\
\hline
\end{tabular}

Table 3: the result of F1.

The quality of qualified personnel capital in social benefit $=$ F2 (quality, ability).

Where F2 is a binary monotone increasing linguistic-valued mapping, which can be depicted as follows:

Suppose that

(1) The linguistic value set of evaluating quality is \{bad, fair, good, excellent\}.

(2) The linguistic value set of evaluating ability is \{little, middling, big\}.

F2 can be given by Table 4 .

\begin{tabular}{|l|l|l|l|}
\hline F2 & Little & Middling & Big \\
\hline Bad & Bad & Bad & Middling \\
\hline Fair & Bad & Middling & Good \\
\hline Good & Middling & Good & Very good \\
\hline Excellent & Good & Very good & Very good \\
\hline
\end{tabular}

Table 4: the result of F2. 


\subsection{Depiction of economic benefit}

Economic benefit $=$ S2 (the quantity of qualified personnel capital in economic benefit, the quality of qualified personnel capital in economic benefit), Where, F2 is a binary monotone increasing linguisticvalued mapping, which can be depicted as follows.

Suppose that (1) The linguistic set of the quantity of qualified personnel capital in economic benefit is \{little, middling, big\}. (2) The linguistic set of the quality of qualified personnel capital in economic benefit is $\{\mathrm{bad}$, fair, good, excellent $\}$. S2 can be given by Table 5 .

\begin{tabular}{|l|l|l|l|l|}
\hline \multicolumn{1}{|c|}{ S2 } & Bad & Fair & Good & Excellent \\
\hline Little & Little & Little & Middling & Middling \\
\hline Middling & Middling & Middling & Big & Big \\
\hline Big & Middling & Big & Big & Big \\
\hline
\end{tabular}

Table 5: the result of S2.

The quantity of qualified personnel capital in economic benefit $=\mathrm{F} 3$ (quality, potentiality)

Where F3 is a binary monotone increasing linguistic-valued mapping, which can be depicted as follows.

Suppose

(1) The linguistic value set of evaluating predisposition is $\{\mathrm{bad}$, fair, good, excellent\}.

(2) The linguistic value set of evaluating potentiality is \{little, middling, big\}, and F3 can be given by Table 6 .

\begin{tabular}{|l|l|l|l|}
\hline F3 & Little & Middling & Big \\
\hline Bad & Little & Little & Middling \\
\hline Fair & Little & Middling & Middling \\
\hline Good & Middling & Middling & Big \\
\hline Excellent & Middling & Big & Big \\
\hline
\end{tabular}

The quality of qualified personnel capital in economic benefit = F4 (quality, potentiality) Where F4 is a binary monotone increasing linguistic-valued mapping, which can be depicted as follows:

Suppose (1) The linguistic value set of evaluating predisposition is $\{\mathrm{bad}$, fair, good, excellent\}. (2) The linguistic value set of evaluating ability is \{little, middling, big\}. F4 can be given by Table 7 .

\begin{tabular}{|l|l|l|l|}
\hline F4 & Little & Middling & Big \\
\hline Bad & Bad & Bad & Fair \\
\hline Fair & Bad & Fair & Good \\
\hline Good & Fair & Good & Excellent \\
\hline Excellent & Good & Excellent & Excellent \\
\hline \multicolumn{4}{|l}{ Table 7: the result of F4. }
\end{tabular}

\subsection{Depiction of quality}

Quality $=M_{1}$ (the construction of ability of qualified personnel resource) Where M1 is a binary monotone increasing linguistic-valued mapping, which can be depicted as follows.

Suppose (1) The linguistic set quality of qualified personnel resource is \{little, middling, big\}, and $\mathrm{M}_{1}$ : \{little, middling, big\} \{bad, fair, good, excellent\},

$$
\begin{aligned}
& \text { little } \mapsto \text { fair } \\
& \text { middling } \mapsto \text { good } \\
& \text { big } \mapsto \text { excellent }
\end{aligned}
$$

\subsection{Depiction of potentiality}

Potentiality $=$ M2 (the construction of ability of qualified personnel resource)

where M2 is a binary monotone increasing linguisticvalued mapping, which can be depicted as follows:

Suppose

(1) The linguistic set of the potentiality of qualified personnel resource is \{little, middling, big\}, and

M2 $\{$ little, middling, big $\} \longrightarrow\{$ bad, fair, good, excellent $\}$,

$$
\begin{aligned}
& \text { little } \mapsto \text { fair } \\
& \text { middling } \mapsto \text { good } \\
& \text { big } \mapsto \text { excellent }
\end{aligned}
$$

\subsection{Depiction of the construction of ability}

Construction of ability $=\mathrm{N}$ (social condition, the self's condition).

Where $\mathrm{N}$ is a binary monotone increasing linguistic-valued mapping, which can be depicted as follows:

Suppose

(1) The linguistic set of the social condition and the self's condition are $\{\mathrm{bad}$, fair, good, excellent $\}$.

$\mathrm{N}$ can be given by Table 8 .

\begin{tabular}{|l|l|l|l|l|}
\hline \multicolumn{1}{|c|}{$\mathrm{N}$} & Bad & Fair & Good & Excellent \\
\hline Bad & Little & Little & Little & Middling \\
\hline Fair & Little & Little & Middling & Big \\
\hline Good & Little & Middling & Big & Big \\
\hline Excellent & Middling & Big & Big & Big \\
\hline
\end{tabular}

Table 8: the result of $\mathrm{N}$. 
The social condition $=\mathrm{G}$ (idea, structural metal, mechanism, cultivation, environment)

Where, $G$ is five variables of monotonous linguistic value with increasing that can be depicted as follows:

Suppose that

(1) The linguistic set of the social condition is $\mathrm{A}=\{\mathrm{bad}$, fair, good, excellent $\}$.

(2) The linguistic value sets of evaluating idea is $\mathrm{A} 1=\{$ out-of-date, more new, very new $\}$.

(3) The linguistic value sets of evaluating structural metal A2=is \{unreasonable, more reasonable, very reasonable .

(4) The linguistic value sets of evaluating mechanism is $\mathrm{A} 3=\{\mathrm{bad}$, fair, good $\}$.

(5) The linguistic value sets of evaluating cultivation is $\mathrm{A} 4=$ (weakness, fair, mightiness $\}$.

(6) The linguistic sets of evaluating environment is $\mathrm{A} 5=\{\mathrm{bad}$, fair, good, excellent $\}$.

And then

$\mathrm{G}: \mathrm{A} 1 \times \mathrm{A} 2 \times \mathrm{A} 3 \times \mathrm{A} 4 \times \mathrm{A} 5 \longrightarrow \mathrm{A}$

(out-of-date, unreasonable, bad, weakness, bad) $\mapsto$ bad

(out-of-date, unreasonable, bad, weakness, middling) $\mapsto$ bad

(out-of-date, unreasonable, bad, weakness, good) $\mapsto$ bad

(out-of-date, more reasonable, bad, weakness, very good) $\mapsto$ middling

(out-of-date, more reasonable, bad, fair, very good) $\mapsto$ middling

(out-of-date, more reasonable, bad, fair, good) $\mapsto$ middling

(out-of-date, more reasonable, bad, fair, middling) $\mapsto$ middling

(more new, more reasonable, bad, fair, middling) $\mapsto$ middling

(more new, more reasonable, fair, fair,

bad) $\mapsto$ middling

(more new, more reasonable, fair, fair, middling) $\mapsto$ middling

(more new, more reasonable, fair, fair, good) $\mapsto$ good

(more new, more reasonable, good, fair, good $) \mapsto \operatorname{good}$

(more new, more reasonable, fair, good, good) $\mapsto$ good

(more new, more reasonable, good, mightiness, good) $\mapsto \operatorname{good}$

(more new, very reasonable, good, mightiness, good) $\mapsto$ good

(very new, very reasonable, good, mightiness, good) $\mapsto \operatorname{good}$

(very new, very reasonable, fair, mightiness, excellent) $\mapsto$ good (very new, very reasonable, good, fair, good $) \mapsto \operatorname{good}$

(very new, very reasonable, good, fair, excellent) $\mapsto$ good

(very new, very reasonable, very good, mightiness, excellent) $\mapsto$ excellent

\section{Conclusions}

We put forward detailed description using linguistic variables for the structure of evaluation of the transform. The model based on linguistic value presented in this paper can be used to explain the principle of transferring qualified personnel resource to qualified personnel capital. It must be pointed out that the process and the evaluation of the transform are very complex and difficult, so it's useful to study on the actual application according to people's habit of thought.

\section{References}

[1] V. A. Alexander, Human capital approach to economic development New Metropolitan, Delhi, 1983.

[2] R. Amit and B. Monica, Human resources management processes: a value-creating source of competitive advantage, European Management Journal, 17(2): 174-181, 1999.

[3] B., Debasis, On the model selection to represent human capital distribution - an empirical study, Journal of Statistical Planning and Inference, 112 (1-2): 213-220, 2003.

[4] G. S. Beker, Investment in human capital: a theoretical analysis, Journal of Political Economy, 70(5): 9-49,1962.

[5] F. Herrera, and E. Herrera-Viedma, Linguistic decision analysis: steps for solving decision problems under linguistic information, Fuzzy Sets and Systems, 115(1): 67-82,2000.

[6] L.A.Zadeh, Fuzzy Logic=Computing with Words, IEEE Transactions on Fuzzy Systems, 4(2): 103$111,1996$.

[7] T. P. Schultz, Human capital, schooling and health, Economics and Human Biology 1(2): $207-$ 221,2003.

[8] Y. Xu, X. Y. Zeng and D. Ruan, On Normalization of Comprehensive Evaluation System with Complex Uncertain Information, Journal of Donghua University, 21 (3): 30-34,2004.

[9] Y. Xu, D. Ruan, K.Y. Qin and J. Liu, Latticevalued logic, Springer-verlag, 2003. 